\title{
Structural and Elastic Properties of Li-Ni Ferrite
}

\author{
S. A. Mazen and T. A. Elmosalami \\ Magnetic Semiconductor Lab, Physics Department, Faculty of Science, Zagazig University, Zagazig, Egypt
}

Correspondence should be addressed to S. A. Mazen, dr.saidmazen@gmail.com

Received 24 September 2011; Accepted 31 October 2011

Academic Editors: S. Balamurugan and K. Matsuhira

Copyright ( 2011 S. A. Mazen and T. A. Elmosalami. This is an open access article distributed under the Creative Commons Attribution License, which permits unrestricted use, distribution, and reproduction in any medium, provided the original work is properly cited.

\begin{abstract}
Li-Nickel ferrites with the chemical formula $\mathrm{Li}_{0.5-0.5 x} \mathrm{Ni}_{x} \mathrm{Fe}_{2.5-0.5 x} \mathrm{O}_{4}(0.0 \leq x \leq 1.0)$ have been prepared by the ceramic method. The spinel structure in homogenous state was realized by X-ray diffraction analysis. The lattice parameter has been determined for each composition and found to be nearly constant over the whole range of Ni concentration $(=0.83 \mathrm{~nm} \pm 0.01)$. The cation distribution for each composition has been suggested. The experimental and theoretical lattice constants were found to be in good agreement with each other confirming the agreeability of the suggested cation distribution. The analysis of IR spectra indicates the presence of splitting in the absorption band due to the presence of small amounts of $\mathrm{Fe}^{2+}$ ions in the ferrite system. The force constants for tetrahedral and octahedral sites have been determined. Young's modulus $(E)$, rigidity modulus $(G)$, bulk modulus $(B)$, Debye temperature $\left(\theta_{D}\right)$, and transverse $\left(V_{t}\right)$ and longitudinal $\left(V_{l}\right)$ wave velocities have been determined. The variation of elastic moduli with composition has been interpreted in terms of binding forces between the atoms of spinal lattice.
\end{abstract}

\section{Introduction}

The substituted lithium ferrites are promising materials for microwave applications because of their low cost, excellent temperature performance, and squareness of the hysteresis loops [1]. Li ferrites are also suitable for the multilayer chip inductors (MLCIs) as the laminating ferrite layers because of their low sintering temperature, high Curie temperature, and excellent electromagnetic properties at high frequency [2].

There are many researches that have been reported in the literature on the studies of $\mathrm{Li}-\mathrm{Zn}, \mathrm{Li}-\mathrm{Mg}, \mathrm{Li}-\mathrm{Ti}, \mathrm{Li}-\mathrm{Cd}$, $\mathrm{Li}-\mathrm{Cu}$, and Li-Ga ferrites [3-8]. However, little information is available in the literature regarding the Li-Ni ferrite. The relative site preference of $\mathrm{Li}^{+1}, \mathrm{Fe}^{+3}$, and $\mathrm{Ni}^{+2}$ in the spinel lattice in the Li-Ni ferrite system was studied by Trivedi et al. [9]. The cation distributions have been determined through $\mathrm{X}$-ray diffraction and confirmed by magnetization measurements. It was found that a greater percentage of $\mathrm{Li}^{+1}$ ions occupy the A-sites in the Ni-rich samples. Also, P.V. Reddy et al. have reported on the investigation of the cation distribution, magnetization, and dielectric properties of $\mathrm{Li}-\mathrm{Ni}$ ferrite system [10-12].

The elastic constants are of much importance because they reveal the nature of binding forces in solids and to understand the thermal properties of the solids. The ultrasonic pulse transmission technique (UPT) is the most common technique for elastic constants and Debye temperature determination [13]. A new method based on infrared spectroscopy has been developed by Modi et al., to study the elastic properties of spinel ferrites [14].

The aim of this present work is to investigate the structural and elastic properties of the ferrite system $\mathrm{Li}_{0.5-0.5 x} \mathrm{Ni}_{x}$ $\mathrm{Fe}_{2.5-0.5 x} \mathrm{O}_{4}(0.0 \leq x \leq 1.0)$ through $\mathrm{X}$-ray and IR analysis.

\section{Experimental Technique}

The measurements were carried out on polycrystalline samples of stoichiometric composition of $\mathrm{Li}_{0.5-0.5 x} \mathrm{Ni}_{x} \mathrm{Fe}_{2.5-0.5 x}$ $\mathrm{O}_{4}$, with $(x=0,0.1,0.3,0.5,0.7,0.9$, and 1.0$)$. The samples were prepared by the usual ceramic technique. The starting oxides $\left(\mathrm{Fe}_{2} \mathrm{O}_{3}, \mathrm{Li}_{2} \mathrm{CO}_{3}\right.$, and $\left.\mathrm{NiO}\right)$ with high purity were mixed and grounded in a very fine powder. The mixtures were presintered at $800^{\circ} \mathrm{C}$ for $10 \mathrm{~h}$. The powders were then regrounded, compressed in the toroidal and pelletized shape, and finally sintered at $1200^{\circ} \mathrm{C}$ for $10 \mathrm{hrs}$ in static air. Then they were cooled gradually to room temperature with rate of $2{ }^{\circ} \mathrm{C}$ per minute. A monophase spinel structure was recorded 


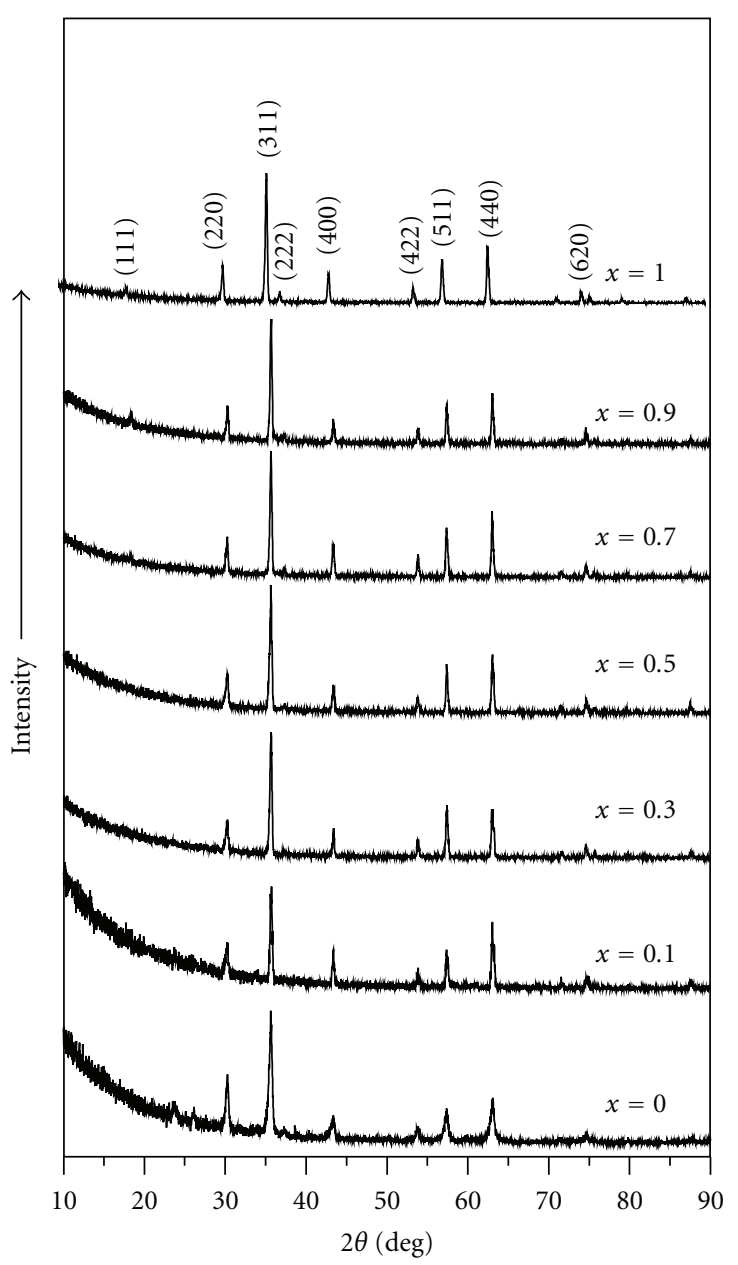

Figure 1: X-ray diffraction patterns of $\mathrm{Li}_{0.5} \mathrm{Ni}_{x} \mathrm{Fe}_{2.5-0.5 x} \mathrm{O}_{4}$ (where $x=0.0,0.1,0.3,0.3,0.5,0.7,0.9$, and 1.0).

for all compositions using X-ray diffractometer, XRD, employing $\mathrm{Cu} \mathrm{K}_{\alpha}$ radiation $(\lambda=1.5405 \AA)$ (type Philips X'Pert Diffractometer). The theoretical X-ray density $\left(d_{x}\right)$ of the samples was calculated using the formula $\left(d x=8 M / \mathrm{Na}^{3}\right)$ where $M$ is the molecular weight, $N$ is Avogadro's number, and $a$ is the lattice parameter. Also, the apparent density was measured using the Archimedes method by weighting the prepared samples in toluene employing the formula $d_{\mathrm{app}}=$ $\left(w_{1} /\left(w_{1}-w_{2}\right)\right) d_{\mathrm{tol}}$, where $w_{1}, w_{2}$ are the weights of the sample in air and toluene, respectively, and $d_{\text {tol }}$ is the density of toluene. Further, The porosity percentage $(P \%)$ was calculated according to the relation $p=\left(1-d_{\mathrm{app}} / d_{x}\right) \%$. The scanning electron micrographs (SEMs) were taken for all samples using (JXA-840A Electro Probe Microanalyzer). The average grain diameter " $D$ " was calculated by the line intercept method. IR spectra in the range from 200 to $1000 \mathrm{~cm}^{-1}$ were recorded at room temperature using the infrared spectrometer (model 1430, Perkin Elmer).

\section{Results and Discussion}

3.1. X-ray Diffraction Analysis. The single-phase cubic spinel formation of the compositions of the ferrite system,
$\mathrm{Li}_{0.5-0.5 x} \mathrm{Ni}_{x} \mathrm{Fe}_{2.5-0.5 x} \mathrm{O}_{4}(x=0,0.1,0.3,0.5,0.7,0.9$, and 1.0), has been confirmed from X-ray diffraction patterns. Figure 1 depicts typical XRD patterns for all studied samples. No impurity phases have been detected from X-ray charts. The main reflection planes of the spinel structure have been shown and listed in Table 1 for all patterns with $d$-spacing values and relative intensity ratios in comparison with those of the JCPDS card of both $\mathrm{Li}_{0.5} \mathrm{Fe}_{2.5} \mathrm{O}_{4}$ and $\mathrm{NiFe}_{2} \mathrm{O}_{4}$ ferrites. The experimental lattice parameter $\left(a_{\exp }\right)$ was calculated according to the following equation:

$$
a_{\exp }=d_{(h k l)}\left(h^{2}+k^{2}+l^{2}\right)^{1 / 2},
$$

where $d$ is the interplanar distance of each plane and $(h k l)$ are Miller indices. The obtained values of " $a_{\exp }$ " are listed in Table 2. From this table, it is found that $a_{\exp }$ does not vary with $x\left(a_{\exp }=0.83 \mathrm{~nm} \pm 0.01\right)$. This behaviour may be attributed to the values of ionic radii of the ions. The replacement of $\mathrm{Fe}^{3+}$ ions $(0.064 \mathrm{~nm})$ and $\mathrm{Li}^{+}$ions $(0.073 \mathrm{~nm})$ by $\mathrm{Ni}^{2+}$ ions $(0.069 \mathrm{~nm})$ according to

$$
\begin{aligned}
& 2 \mathrm{Ni}^{2+} \longleftrightarrow \mathrm{Li}^{+}+\mathrm{Fe}^{3+} \\
& (0.14 \mathrm{~nm}) \approx(0.14 \mathrm{~nm})
\end{aligned}
$$

Since there is no difference between $r_{\mathrm{Li}^{+}}+r_{\mathrm{Fe}^{3+}}$ and $2 r_{\mathrm{Ni}^{2+}}$, the lattice parameter is constant over the whole concentration range.

3.2. Cation Distribution and Theoretical Lattice Parameter. It is known that there is a correlation between the ionic radii of both $A$ - and $B$-sublattices and the lattice parameter. Then, the lattice parameter can be calculated theoretically using the following equation [15]:

$$
a_{\mathrm{th}}=\frac{8}{3 \sqrt{3}}\left[\left(r_{A}+R_{o}\right)+\sqrt{3}\left(r_{B}+R_{o}\right)\right],
$$

where $R_{o}$ is the radius of the oxygen ion $(0.132 \mathrm{~nm})$ and $r_{A}$ and $r_{B}$ are the ionic radii of tetrahedral $(A$-site) and octahed$\mathrm{ral}\left(B\right.$-site), respectively. In order to calculate $r_{A}$ and $r_{B}$, it is necessary to suggest a suitable cation distribution. The knowledge of cation distribution and spin alignment is essential to understand the magnetic properties of spinel ferrite. The interesting electrical and magnetic properties of spinel ferrite arise from the ability of distribution of cations among the tetrahedral $(A)$ and octahedral $(B)$ sites. The investigation of cation distribution provides a mean to develop materials with desired properties which are useful for many devices [16]. In the light of the previous work reported on $\mathrm{Li}-\mathrm{Ni}$ ferrite [9] the cation of the present studied samples has been suggested as listed in Table 2 . Using the suggested cation distribution data, the mean ionic radii of tetrahedral A-site $\left(r_{A}\right)$ and octahedral B-site $\left(r_{B}\right)$ were calculated and given in Table 2. As observed from the table, $r_{A}$ and $r_{B}$ are constant for all values of $x$. This behaviour may be due to the constant value of the lattice parameter with different values of composition $(x)$. Furthermore, the values of the theoretical lattice parameters ath were calculated using formula (3). It is observed from the table that both $a_{\exp }$ and ath are the same 
TABLE 1: The calculated $d$-spacing of the recorded peaks and the corresponding relative intensities $I / I_{o}$ with the data of (JCPDS card).

\begin{tabular}{|c|c|c|c|c|c|c|c|c|c|c|c|c|c|c|c|c|c|c|c|}
\hline & 036 & & & & & $=0.1$ & & 0.3 & & & $x=$ & $=0.7$ & $x=$ & $=0.9$ & & 1.0 & $\underset{(\mathrm{JCP}}{\mathrm{Ni}}$ & DS ca & \\
\hline plane & $(d) \AA$ & $I / I_{o} \%$ & $(d) \AA$ & $I / I_{o} \%$ & (d) $\AA$ & $I / I_{o} \%$ & (d) $\AA$ & $I / I_{o} \%$ & $(d) \AA$ & $I_{0} \%$ & $(d) \AA$ & $I / I_{o} \%$ & $(d) \AA$ & $I / I_{o} \%$ & $(d) \AA$ & $I / I_{o} \%$ & plane & $(d) \AA$ & $I / I_{o} \%$ \\
\hline 111 & 5.89 & 7 & - & - & - & - & - & - & - & - & - & - & 4.82 & 7.77 & 4.81 & 6.62 & 111 & 483 & 30 \\
\hline 210 & 3.73 & 14 & 3.75 & 9.65 & - & - & - & - & - & - & - & - & - & - & - & - & - & - & - \\
\hline 211 & 3.41 & 9 & 3.41 & 10.53 & - & - & - & - & - & - & - & - & - & - & - & - & - & - & - \\
\hline 220 & 2.95 & 35 & 2.95 & 44.85 & 2.95 & 34.8 & 2.95 & 25.55 & 2.94 & 26.54 & 2.95 & 27.84 & 2.94 & 25.45 & 2.94 & 37.9 & 220 & 2.95 & 50 \\
\hline 311 & 2.51 & 100 & 2.52 & 100 & 2.52 & 100 & 2.51 & 100 & 2.52 & 100 & 2.52 & 100 & 2.52 & 100 & 2.52 & 100 & 311 & 2.52 & 100 \\
\hline 222 & 2.4 & 3 & - & - & - & - & 2.42 & 2.98 & 2.41 & 10.96 & 2.41 & 4.64 & 2.41 & 4.26 & 2.41 & 10.66 & 222 & 2.42 & 10 \\
\hline 400 & 2.08 & 16 & 2.08 & 15.98 & 2.09 & 39.06 & 2.09 & 22.33 & 2.09 & 22.76 & 2.08 & 24.64 & 2.09 & 18.27 & 2.09 & 32.55 & 400 & 2.09 & 40 \\
\hline 422 & 1.7 & 12 & 1.7 & 10.01 & 1.7 & 14.97 & 1.7 & 13.26 & 1.7 & 13.13 & 1.7 & 16.15 & 1.7 & 9.46 & 1.7 & 16.88 & 422 & 1.71 & 20 \\
\hline 511 & 1.6 & 32 & 1.61 & 24.85 & 1.61 & 38.24 & 1.61 & 37.9 & 1.6 & 37.9 & 1.61 & 38.58 & 1.6 & 32.76 & 1.6 & 50.98 & 511 & 1.61 & 50 \\
\hline 440 & 1.47 & 41 & 1.47 & 36.02 & 1.48 & 68.54 & 1.48 & 39.33 & 1.48 & 44.27 & 1.48 & 50.31 & 1.48 & 31.37 & 1.48 & 78.04 & 440 & 1.48 & 60 \\
\hline 620 & 1.32 & 4 & 1.32 & 1.96 & 1.32 & 5.73 & 1.32 & 5.02 & 1.32 & 4.51 & 1.32 & 3.91 & 1.32 & 3 & 1.32 & 6.78 & 620 & 1.32 & 5 \\
\hline 533 & 1.27 & 10 & - & - & 1.27 & 10.25 & 1.27 & 11.3 & 1.27 & 11.16 & 1.27 & 9.03 & 1.27 & 9.75 & 1.27 & 15.73 & 533 & 1.28 & 15 \\
\hline 622 & 1.26 & 2 & - & - & - & - & 1.26 & 2.71 & 1.26 & 3.88 & 1.26 & 3.24 & 1.26 & 1 & 1.26 & 7.33 & 622 & 1.26 & 5 \\
\hline 444 & 1.2 & 2 & - & - & - & - & 1.2 & 1.9 & 1.2 & 4.06 & 1.2 & 2.3 & 1.2 & 1 & 1.2 & 5.58 & 444 & 1.21 & 10 \\
\hline 642 & 1.11 & 5 & - & - & 1.11 & 6.08 & 1.11 & 4.13 & 1.11 & 9.38 & 1.11 & 3.98 & 1.11 & 3 & 1.11 & 6.73 & 642 & 1.12 & 10 \\
\hline
\end{tabular}

Table 2: The Cation distribution, ionic radii of $A$ - and $B$-sites, experimental and theoretical lattice constants and particle size of Li-Ni ferrite samples (with $0.0 \leq x \leq 1.0$ ).

\begin{tabular}{|c|c|c|c|c|c|c|c|c|}
\hline$x$ & Chemical formula & $A$-site & $B$-site & $r_{A}(\mathrm{~nm})$ & $r_{B}(\mathrm{~nm})$ & $a_{\exp }(\mathrm{nm})$ & $a_{\mathrm{th}}(\mathrm{nm})$ & $t(\mathrm{~nm})$ \\
\hline 0 & $\mathrm{Li}_{0.5} \mathrm{Fe}_{2.5} \mathrm{O}_{4}$ & $\left(\mathrm{Fe}_{1}\right)$ & {$\left[\mathrm{Li}_{0.50} \mathrm{Fe}_{1.50}\right] \mathrm{O}_{4}$} & 0.06 & 0.07 & 0.83 & 0.83 & 40.24 \\
\hline 0.1 & $\mathrm{Li}_{0.45} \mathrm{Ni}_{0.1} \mathrm{Fe}_{2.45} \mathrm{O}_{4}$ & $\left(\mathrm{Li}_{0.05} \mathrm{Fe}_{0.95}\right)$ & {$\left[\mathrm{Li}_{0.4} \mathrm{Ni}_{0.1} \mathrm{Fe}_{1.5}\right] \mathrm{O}_{4}$} & 0.06 & 0.07 & 0.83 & 0.83 & 51.65 \\
\hline 0.3 & $\mathrm{Li}_{0.35} \mathrm{Ni}_{0.3} \mathrm{Fe}_{2.35} \mathrm{O}_{4}$ & $\left(\mathrm{Li}_{0.02} \mathrm{Fe}_{0.98}\right)$ & {$\left[\mathrm{Li}_{0.33} \mathrm{Ni}_{0.3} \mathrm{Fe}_{1.37}\right] \mathrm{O}_{4}$} & 0.06 & 0.07 & 0.83 & 0.83 & 50.50 \\
\hline 0.5 & $\mathrm{Li}_{0.25} \mathrm{Ni}_{0.5} \mathrm{Fe}_{2.25} \mathrm{O}_{4}$ & $\left(\mathrm{Ni}_{0.02} \mathrm{Fe}_{0.98}\right)$ & {$\left[\mathrm{Li}_{0.25} \mathrm{Ni}_{0.48} \mathrm{Fe}_{1.27}\right] \mathrm{O}_{4}$} & 0.06 & 0.07 & 0.83 & 0.83 & 56.71 \\
\hline 0.7 & $\mathrm{Li}_{0.15} \mathrm{Ni}_{0.7} \mathrm{Fe}_{2.15} \mathrm{O}_{4}$ & $\left(\mathrm{Ni}_{0.025} \mathrm{Fe}_{0.975}\right)$ & {$\left[\mathrm{Li}_{0.15} \mathrm{Ni}_{0.675} \mathrm{Fe}_{1.175}\right] \mathrm{O}_{4}$} & 0.06 & 0.07 & 0.83 & 0.83 & 58.83 \\
\hline 0.9 & $\mathrm{Li}_{0.05} \mathrm{Ni}_{0.9} \mathrm{Fe}_{2.05} \mathrm{O}_{4}$ & $\left(\mathrm{Ni}_{0.03} \mathrm{Fe}_{0.97}\right)$ & {$\left[\mathrm{Li}_{0.05} \mathrm{Ni}_{0.87} \mathrm{Fe}_{1.08}\right] \mathrm{O}_{4}$} & 0.06 & 0.07 & 0.83 & 0.83 & 49.53 \\
\hline 1 & $\mathrm{NiFe}_{2} \mathrm{O}_{4}$ & $\left(\mathrm{Ni}_{0.03} \mathrm{Fe}_{0.97}\right)$ & {$\left[\mathrm{Ni}_{0.97} \mathrm{Fe}_{1.03}\right] \mathrm{O}_{4}$} & 0.06 & 0.07 & 0.83 & 0.83 & 53.25 \\
\hline
\end{tabular}

for all values of $x$, which confirms the agreeability of the suggested cation distribution.

The X-ray density $\left(d_{x}\right)$ for each composition was calculated. The effect of Ni-content $(x)$ on the variation of X-ray density is depicted in Figure 2. It is obvious from the figure that $d_{x}$ is increasing linearly with $x$. The observed increase in $d_{x}$ may be due to the increase in the molecular weight of the samples by increasing Ni-content according to formula (2), since the atomic weights of $\mathrm{Ni}, \mathrm{Fe}$, and $\mathrm{Li}$ are 58.69, 55.847, and 6.941, respectively. Further, the apparent density $\left(d_{\mathrm{app}}\right)$ of the above ferrite system was measured via the Archimedes method. The relation between the Ni-content $(x)$ and the apparent density was plotted in Figure 2. It is observed from this figure that $d_{\mathrm{app}}$ increases as $x$ increases till $x=0.5$ only. Then it decreases by further increase in $x$ except for $x=1.0$. This behaviour matches well with the behaviour of $d_{x}$ only in the first range.

The percentage porosity $(P \%)$ of the samples was computed from the values of both $d_{x}$ and $d_{\text {app. }}$. The effect of composition $x$ on the porosity $P \%$ is shown in Figure 3. It is seen form this figure that the porosity is nearly constant in the range of $0.0 \leq x \leq 0.5$, but it increases in the range of
$0.7 \leq x \leq 1.0$. The nearly constant value of $P \%$ in the former range may be due to that the percentage increasing in $d_{\mathrm{app}}$ (about 6.43\%) is bit lower than that of $d_{x}$ (about 6.93\%), then one can expect that porosity remains nearly constant in this range. In the later range, the apparent density $d_{\mathrm{app}}$ decreases by increasing $x$ except for $x=1.0$; however $d_{x}$ is still increasing in this range. The overall effect is the observed increase of porosity as shown clearly in Figure 3. Moreover, it was found that the values of the porosity lie in the range of $5-12 \%$. Such these values indicate the highly dense structure of the prepared samples.

Depending on the broadening of the most 5 intense peaks in XRD patterns, (220), (311), (400), (511), and (440), the particle size of each sample was calculated using the wellknown Sherrer's equation [17]:

$$
t=\frac{0.9 \lambda}{\beta \cos \theta_{B}},
$$

where $t$ is particle size, $\lambda$ is wavelength of $\mathrm{X}$-ray radiation, $\theta_{B}$ is Bragg's angle, and $\beta$ is full width at half maximum. The data of the average particle size calculated for each all sample 


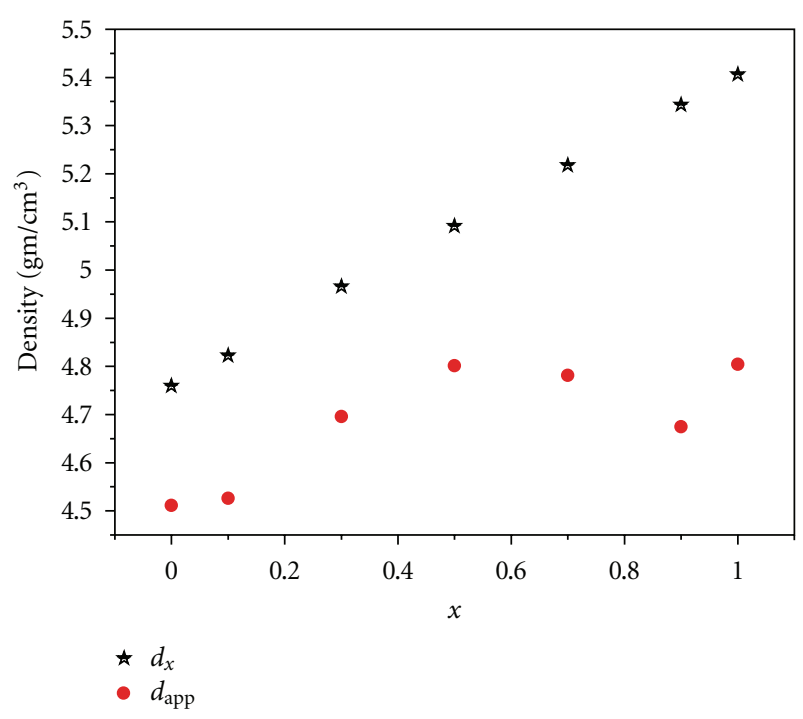

FIGURE 2: The effect of Ni concentration $(x)$ on the variation of Xray density $d_{x}$ and the apparent density $d_{\text {app }}$.

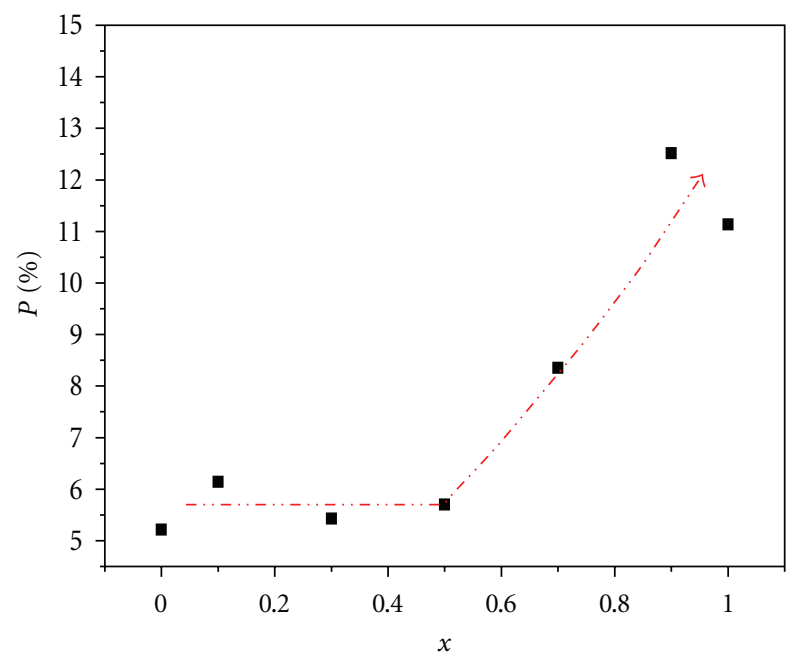

FIGURE 3: The effect of Ni concentration $(x)$ on the variation of porosity $(P \%)$.

are reported in Table 2. As seen from the table, the calculated values of particle size lie in the range of $40-59 \mathrm{~nm}$.

3.3. Grain Diameter. Magnetic and electrical properties are sensitively depending on the microstructure of ferrites. Grain diameter is more an important parameter affecting the magnetic properties of ferrites. Grain growth is closely related to the grain boundary mobility. Recrystallization and grain growth involve the movement of grain boundaries [18]. The SEM micrographs for the fractured surface of the samples are shown in Figure 4. The SEM micrographs indicate the distribution of grains with nonuniform size. The average grain diameter (D) of the samples was calculated from the SEM micrographs. The variation of grain diameter with Nickel content $(x)$ is shown in Figure 5. The values of the grain diameter lie in the range between 6 and $14 \mu \mathrm{m}$. These values are summarized in Table 2 . The highest values were recorded for $x=0.3$ and 0.5 , however the lowest for $x=1.0$ (i.e., $\mathrm{NiFe}_{2} \mathrm{O}_{4}$ ). This variation in grain diameter can be attributed to different factors such as diffusion coefficient and the concentration of dissimilar ions [19]. Obviously, the grains diameters observed by SEM are several times larger than the particle diameters calculated using XRD patterns, which indicates that each grain observed by SEM consists of several particles [20]. Regarding Figures 3 and 5, it is noticed that the larger the grain diameter, the lower the porosity. This behavior could be attributed to the fact that the samples with high porosity contain many pores which formed on the grain boundary.

3.4. IR Spectral Analysis. The IR absorption spectra recorded in the range of $1000-200 \mathrm{~cm}^{-1}$ are shown in Figure 6. The absorption bands are summarized in Table 3. It is a wellknown fact that the normal and inverse cubic spinels have four IR absorption bands signifying the four fundamentals $\left(\nu_{1}^{a}, v_{2}^{a}, v_{3}\right.$, and $\left.v_{4}\right)[21]$.

The IR spectrum of pure Li-ferrite $(x=0.0)$ was discussed previously in more detail by our group [8, 22]. From Figure 6 it is noticeable that the main absorption bands $\left(\nu_{1}^{a}\right.$ and $\nu_{2}^{a}$ ) have appeared in all series of the investigated ferrite system. These two bands are common in almost all spinel ferrites. They are located around 600 and $400 \mathrm{~cm}^{-1}$, respectively. In the present work, the high frequency band $\nu_{1}^{a}$ and the second absorption band $v_{2}^{a}$ are found in the ranges $572-590 \mathrm{~cm}^{-1}$ and $382-404 \mathrm{~cm}^{-1}$, respectively. These are attributed to tetrahedral and octahedral site complexes in spinel structure [23]. The values of $v_{1}^{a}$ are higher than those of $v_{2}^{a}$ indicating that the normal mode of vibration of the tetrahedral complexes is higher than that of the corresponding octahedral site. This may be due to the shorter bond length of the tetrahedral site $\left(R_{A}=1.89 \AA\right)$ than that of the octahedral site $\left(R_{B}=1.99 \AA\right)$. Weaker band $\left(\nu_{3}\right)$ around $327-331 \mathrm{~cm}^{-1}$ has been observed in the samples of $x=0.0,0.1$, and 0.3 only. This band may be due to divalent metal ion-oxygen complexes in octahedral sites. Hence, its appearance can be considered as an evidence of the existence of the divalent iron ions $\mathrm{Fe}^{2+}$ [22]. Moreover, the decrease in the intensity of this band with composition $x$ indicates the decrement of $\mathrm{Fe}^{+2}$ ions by increasing $\mathrm{Ni}$-content in the studied samples.

Another very small shoulders around 707, 667 and $543 \mathrm{~cm}^{-1}$ have appeared in the IR spectra of the samples (with $x=0,0.1$, and 0.3 ) for tetrahedral site then completely disappeared for higher concentration of $\mathrm{Ni}^{2+}$. Such shoulders have been recorded also for $\mathrm{Li}_{0.5} \mathrm{Fe}_{2.5} \mathrm{O}_{4}$ by many authors $[8,24]$. These bands are denoted by $v_{1(1)}, v_{1(2)}$, and $v_{1}^{*}$. It has been shown by Potakova et al. [25] that the presence of $\mathrm{Fe}^{2+}$ ions in ferrites can produce splitting or shoulder of absorption bands. It is attributed to Jahn-Teller distortion produced by $\mathrm{Fe}^{2+}$ ions which locally produce deformation in the crystal field potential and hence splitting of the absorption bands. 


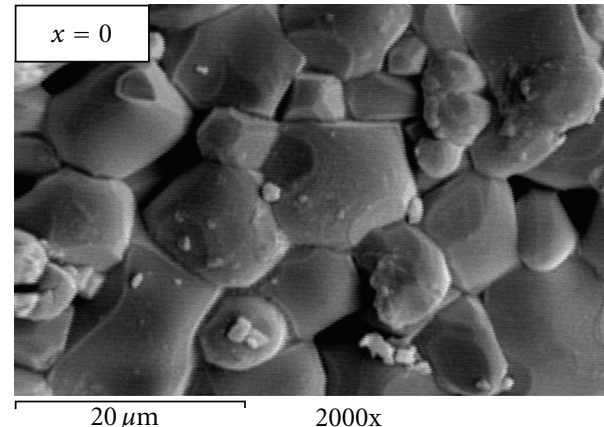

(a)

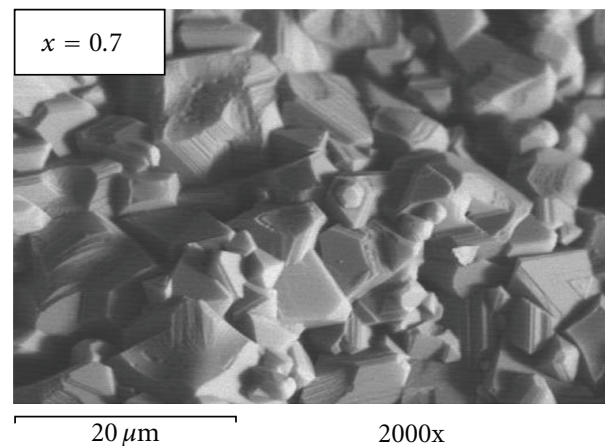

(c)

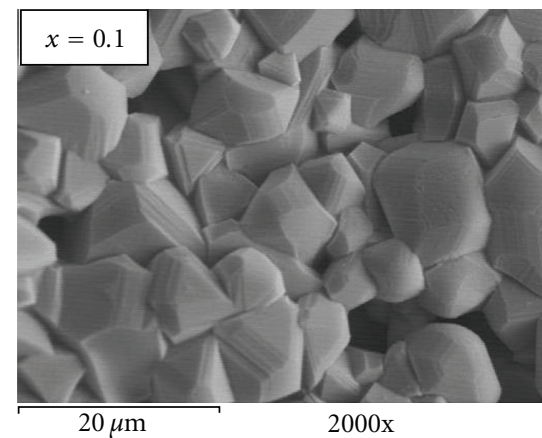

(b)

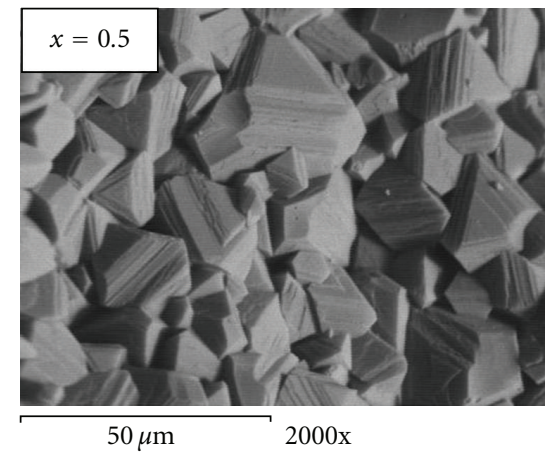

(d)

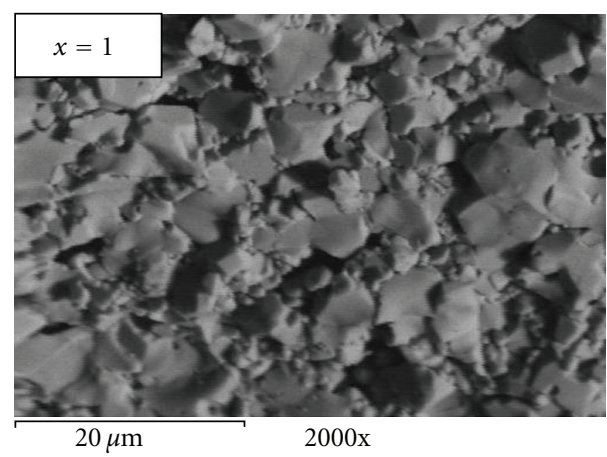

(e)

Figure 4: SEM micrographs for $x=0.0,0.3,0.5,0.7$, and 1.0 .

TABLE 3: IR absorption bands of $\mathrm{Li}_{0.5-0.5 x} \mathrm{Ni}_{x} \mathrm{Fe}_{2.5-0.5 x} \mathrm{O}_{4}$.

\begin{tabular}{|c|c|c|c|c|c|c|c|c|c|}
\hline \multirow{3}{*}{ Sample $(x)$} & \multirow{2}{*}{\multicolumn{4}{|c|}{$\begin{array}{c}\text { Tetrahedral site }(A \text {-site }) \\
\mathrm{Fe}^{3+}-\mathrm{O}^{2-}\left(\mathrm{cm}^{-1}\right)\end{array}$}} & \multicolumn{3}{|c|}{ Octahedral site ( $B$-site) } & \multirow[b]{3}{*}{$v_{4}$} & \multirow[b]{3}{*}{$v_{\text {th }}$} \\
\hline & & & & & \multirow{2}{*}{$\begin{array}{c}\mathrm{Li}-\mathrm{O}\left(\mathrm{LiO}_{4}\right) \\
v_{2(1)}\end{array}$} & \multirow{2}{*}{$\begin{array}{c}\mathrm{Fe}^{3+}-\mathrm{O}^{2-} \\
v_{2}^{\mathrm{a}} \\
\end{array}$} & \multirow{2}{*}{$\begin{array}{c}\text { Divalent } \mathrm{Fe}^{2+} \\
v_{3}\end{array}$} & & \\
\hline & $v_{1(1)}$ & $\nu_{1(2)}$ & $v_{4}^{\mathrm{a}}$ & $v_{1}^{*}$ & & & & & \\
\hline 0.0 & 707 & $667(\mathrm{sh})$ & 576 & $543(\mathrm{sh})$ & 450 & 382 & 327 & 267 & 786 \\
\hline 0.1 & 707 & $672(\mathrm{sh})$ & 577 & $528(\mathrm{sh})$ & 458 & 382 & 331 & 255 & 784 \\
\hline 0.3 & 706 & - & 572 & - & - & 386 & 331 & 257 & 768 \\
\hline 0.5 & - & - & 576 & - & - & 389 & - & 261 & 776 \\
\hline 0.7 & - & - & 573 & - & - & 393 & - & 259 & 772 \\
\hline 0.9 & - & - & 589 & - & - & 404 & - & 255 & 772 \\
\hline 1.0 & - & - & 590 & - & - & 404 & - & 261 & 770 \\
\hline
\end{tabular}

aprimary, sh: shoulder. 


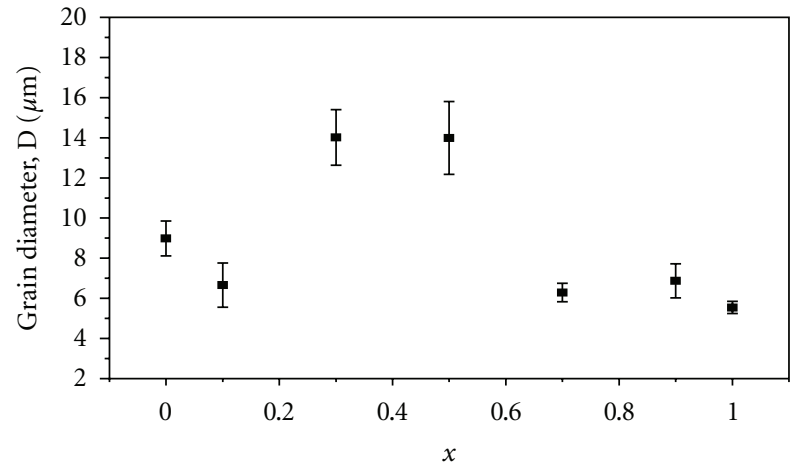

Figure 5: The effect of Ni-content $(x)$ on the grain diameter (D).

According to Tarte [26], the high frequency band $\nu_{2(1)}$ recorded only for $x=0.0$ and $x=0.1$ in the range $450-458 \mathrm{~cm}^{-1}$ could be assigned to $\mathrm{Li}^{+}-\mathrm{O}^{2-}$ complexes on octahedral site. The intensity of this band goes on decreasing with the increase in $x$ since the $\mathrm{Li}^{+}$content decreases with increasing in $x$, so it persists only up to $x=0.1$. Then it completely disappeared for $x \geq 0.3$.

The force constants, for tetrahedral site $\left(k_{t}\right)$ and octahedral site $\left(k_{o}\right)$, were calculated employing the method suggested by Waldron [27]. According to Waldron, the force constants for tetrahedral $A$-sites $\left(k_{t}\right)$ and octahedral $B$-sites $\left(k_{o}\right)$ are given by

$$
\begin{gathered}
k_{t}=7.62 M_{A} \cdot v_{1}^{2} 10^{-7} \mathrm{~N} / \mathrm{m}, \\
k_{\mathrm{o}}=10.62 M_{B} / 2 \cdot v_{2}^{2} 10^{-7} \mathrm{~N} / \mathrm{m},
\end{gathered}
$$

where $M_{A}$ and $M_{B}$ are the molecular weights of cations on $A$ and $B$-sites, respectively, calculated from cation distribution formula suggested in Table 2. The values of the force constants are listed in Table 4. Figure 7 shows the variation of the force constants $K_{t}$ and $K_{o}$ with $(x)$. It can be seen that $K_{t}$ initially decreases at $x=0.1$. Then it increases as $x$ increases from $x=0.3$ up to $x=1.0$. However, $K_{o}$ increases linearly with $x$. Furthermore the calculated values of $K_{t}$ are greater than those of the corresponding values of $K_{o}$. However the values of the bond length of $A$-site $\left(R_{A}\right)$ are smaller than those of $B$-site $\left(R_{B}\right)$. This is due to the inverse proportionality between the bond length and the force constants [24].

3.5. Elastic Properties. The ultrasonic pulse transmission technique (UPT) is the most conventional technique for elastic constants and Debye temperature determination [28]. To study the elastic properties of spinel ferrite and garnet systems, a new technique based on the infrared spectroscopy has been developed by Modi et al. [14, 29, 30]. The different elastic modulii can be evaluated using the following relations.

The bulk modulus $(B)$ of solids is defined as

$$
B=\frac{1}{3}\left(C_{11}+2 C_{12}\right)
$$

where $C_{11}$ and $C_{12}$ are the stiffness constants. But according to Waldron [27] for isotropic materials with cubic symmetry

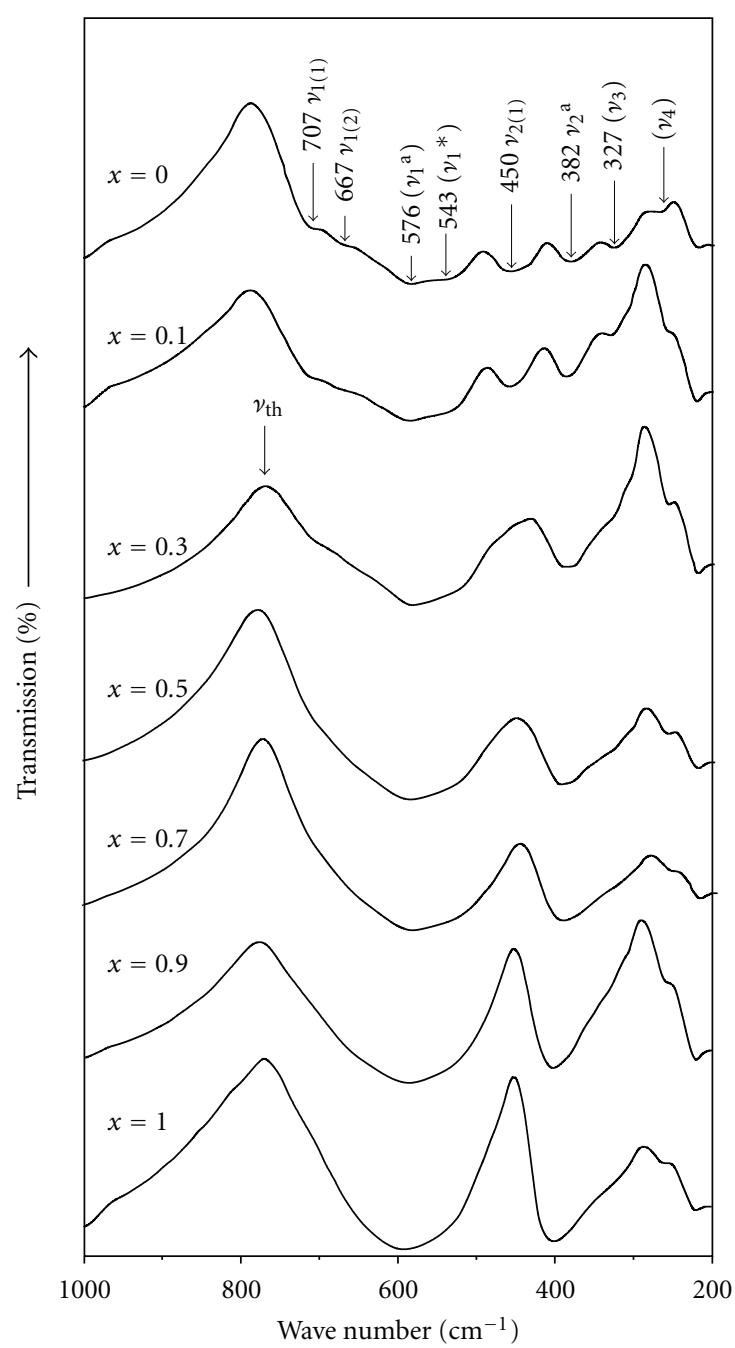

FIGURE 6: The IR transmission spectra of $\mathrm{Li}_{0.5-0.5 x} \mathrm{Ni}_{x} \mathrm{Fe}_{2.5-0.5 x} \mathrm{O}_{4}$ ferrite.

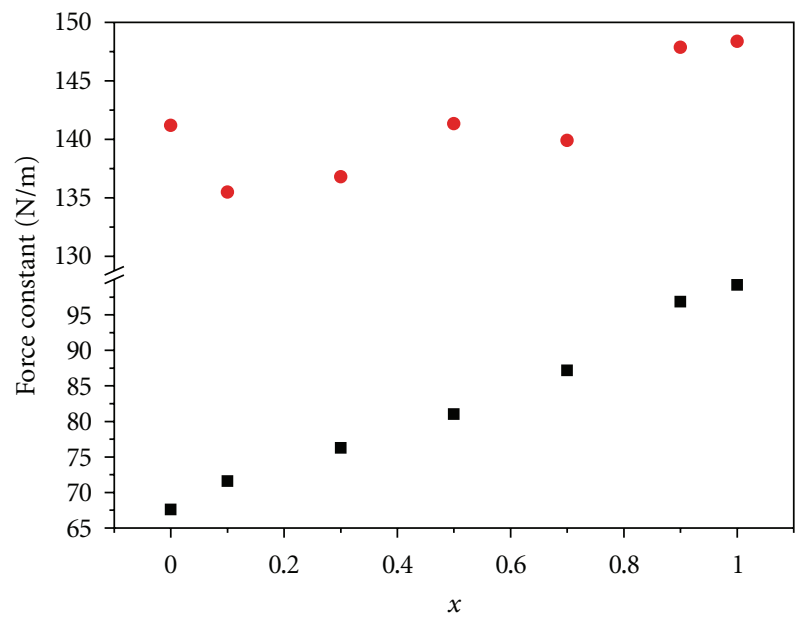

- $K_{o}$

- $K_{t}$

FIGURE 7: The effect of composition on the variation of tetrahedral and octahedral force constants $\left(K_{t}\right.$ and $\left.K_{o}\right)$. 


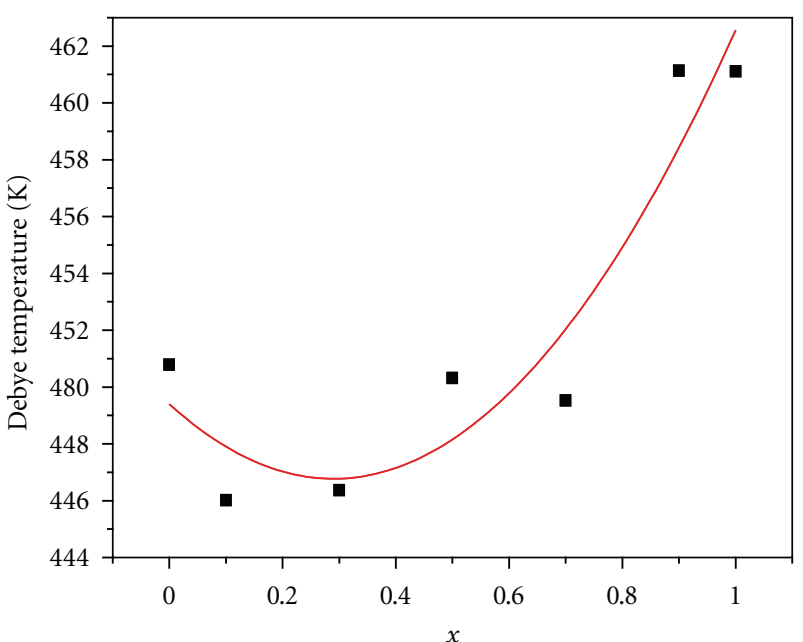

(a)

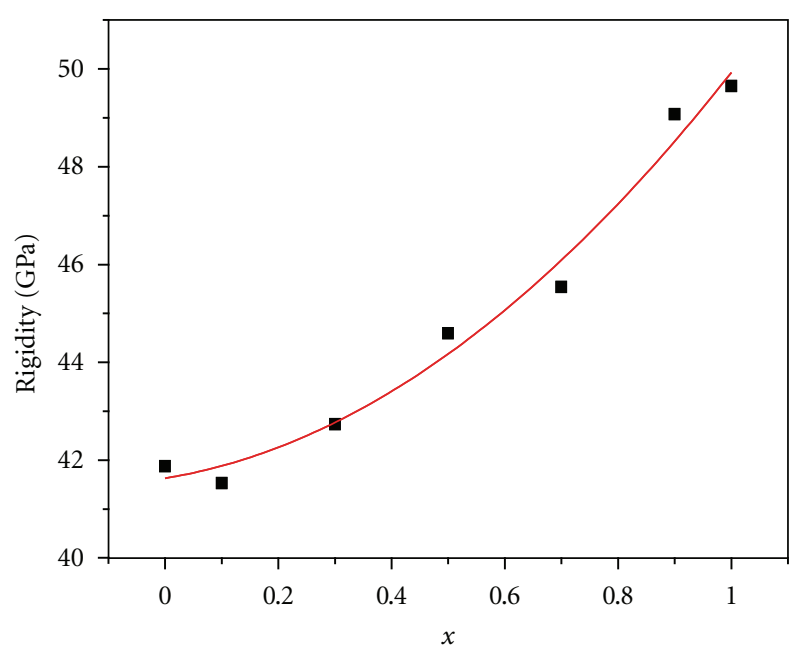

(c)

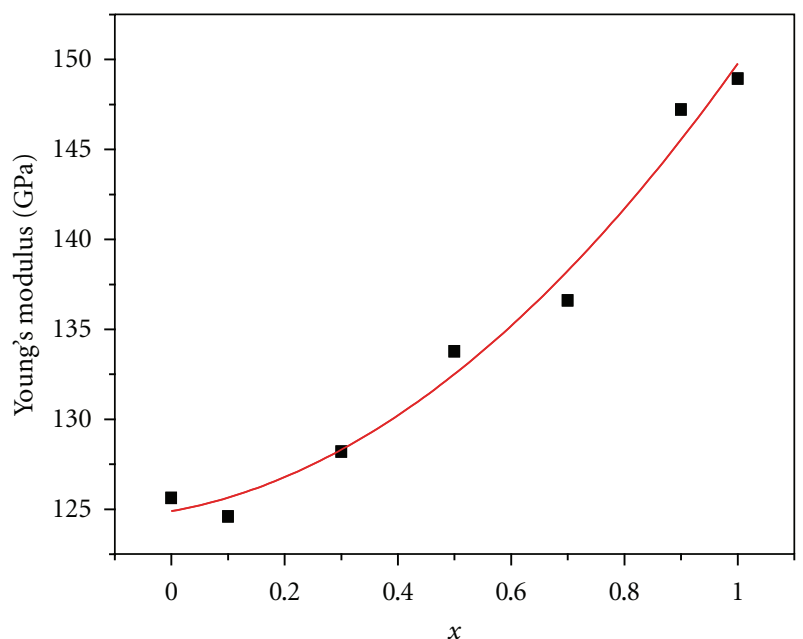

(b)

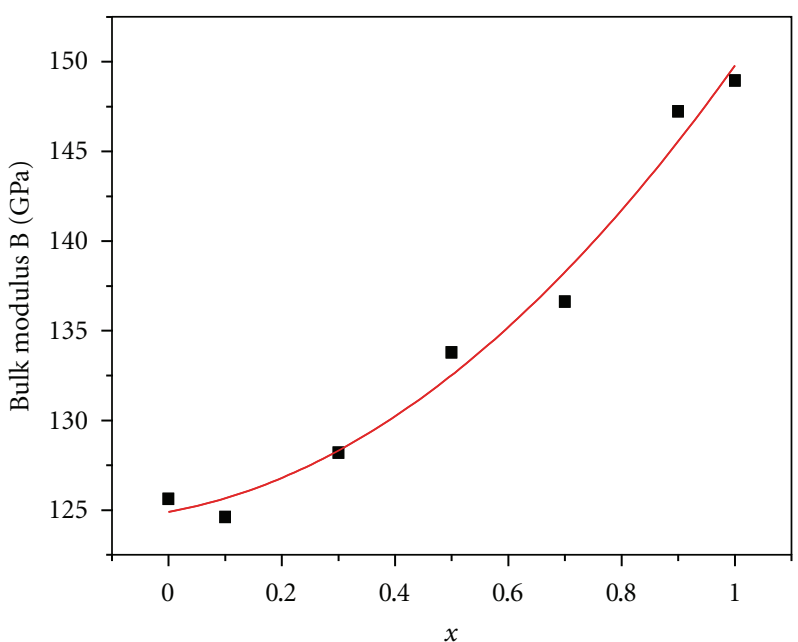

(d)

FIGURE 8: The effect of composition on the variation of Debye temperature and the different elastic moduli.

TABLE 4: The force constants and Elastic constants calculated for Li-Ni ferrite samples.

\begin{tabular}{|c|c|c|c|c|c|c|c|c|c|c|c|c|c|c|}
\hline$x /$ parameter & $\begin{array}{l}M_{1} \\
\left(\mathrm{~K}_{\mathrm{g}}\right.\end{array}$ & $\begin{array}{c}M_{2} \\
\left(\mathrm{~m}^{3}\right) \\
\end{array}$ & $\begin{array}{l}K_{t} \\
\quad(\mathrm{~N} / 1\end{array}$ & $\mathrm{m}^{K_{o}}$ & $C 11$ & $B$ & $E$ & $G$ & $\sigma$ & $V_{I}$ & $\begin{array}{c}V_{t} \\
10^{3} \mathrm{~m} / \mathrm{s}\end{array}$ & $V_{m}$ & $\begin{array}{c}V_{A} \times 10^{-6} \\
\left(\mathrm{~m}^{3}\right)\end{array}$ & $\theta_{D}(\mathrm{~K})$ \\
\hline 0.0 & 0.056 & 0.087 & 141.189 & 67.599 & 125.624 & 125.624 & 125.611 & 41.875 & 0.5 & 5.138 & 2.966 & 3.293 & 6.216 & 450.786 \\
\hline 0.1 & 0.053 & 0.092 & 135.477 & 71.609 & 124.600 & 124.600 & 124.586 & 41.533 & 0.5 & 5.083 & 2.935 & 3.258 & 6.216 & 446.019 \\
\hline 0.3 & 0.055 & 0.096 & 136.796 & 76.275 & 128.202 & 128.202 & 128.187 & 42.734 & 0.5 & 5.081 & 2.933 & 3.257 & 6.193 & 446.368 \\
\hline 0.5 & 0.056 & 0.101 & 141.333 & 81.020 & 133.786 & 133.786 & 133.771 & 44.595 & 0.5 & 5.126 & 2.959 & 3.285 & 6.193 & 450.311 \\
\hline 0.7 & 0.056 & 0.106 & 139.899 & 87.160 & 136.618 & 136.618 & 136.603 & 45.539 & 0.5 & 5.117 & 2.954 & 3.280 & 6.193 & 449.527 \\
\hline 0.9 & 0.056 & 0.112 & 147.858 & 96.827 & 147.223 & 147.223 & 147.207 & 49.074 & 0.5 & 5.249 & 3.031 & 3.365 & 6.194 & 461.131 \\
\hline 1.0 & 0.056 & 0.114 & 148.361 & 99.193 & 148.949 & 148.949 & 148.933 & 49.650 & 0.5 & 5.249 & 3.031 & 3.364 & 6.194 & 461.116 \\
\hline
\end{tabular}

like spinel ferrites and garnets, $C_{11} \approx C_{12}$, therefore, $B=C_{11}$. Also, the force constant $(k)$ is related to the stiffness constant by [ $\left.k=a C_{11}\right]$ [13], where $k$ is the average force constant $\left(k=\left(k_{t}+k_{o}\right) / 2\right)$. Further, the values of the longitudinal elastic wave $\left(V_{l}\right)$ and the transverse elastic wave $\left(V_{t}\right)$ have been determined as follows $[27,28,31]$ :

$$
V_{l}=\left(\frac{C_{11}}{d \mathrm{x}}\right)^{1 / 2}, \quad V_{t}=\frac{V_{l}}{\sqrt{ } 3}
$$


The values of $V_{l}$ and $V_{t}$ are used to calculate the elastic moduli and Debye temperature of the ferrite specimens using the following formulae [31]:

Rigidity modulus $(G)=d_{x} V_{t}^{2}$,

Poisson's ratio $(\sigma)=(3 B-2 G) /(6 B+2 G)$,

Young's modulus $(E)=(1+\sigma) 2 G$,

Mean elastic wave velocity $V_{m}=(1 / 3)\left[\left(2 / V_{l}^{3}\right)+\left(1 / V_{t}^{3}\right)\right]^{-1 / 3}$. All the values of different elastic moduli of the studied Li$\mathrm{Ni}$ ferrite system were calculated and reported in Table 4 . From this table, it can be seen that, $B, E$, and $G$ increase with increasing Ni-content $(x)$. Following Wooster's work [32], the variation of $B, E$, and $G$ with increasing Ni-content $(x)$ may be interpreted in terms of the interatomic bonding. Thus, it can be deduced from the increase of elastic moduli with concentration $(x)$ that the interatomic bonding between various atoms is being strengthened continuously. The values of Poisson's ratio $(\sigma)$ were found to be constant $(\sigma=0.35)$ for all samples. Further these values lie in the range from -1 to 0.5 which is consistent with the theory of isotropic elasticity [33].

The Debye temperature was calculated employing the following formula reported by Raj et al. [31] and listed in Table 4:

$$
\text { Debye temperature }\left(\theta_{D}\right)=\frac{h}{k_{B}}\left[\frac{3 N_{A}}{4 \pi V_{A}}\right]^{1 / 3} \cdot V_{m},
$$

where $V_{A}$ is mean atomic volume given by $\left(M / d_{x}\right) / q, M$ the molecular weight, $q$ is the number of atoms in the formula unit (i.e., 7), and $N_{A}$ is Avogadro's number. Figures 8(a)$8(d)$ show the variation of the Debye temperature $\left(\theta_{D}\right)$ with composition. It is well shown from the figure that $\left(\theta_{D}\right)$ decreases firstly in the range of $0.0 \leq x \leq 0.3$. Further increase of $x(0.3 \leq x \leq 1.0)$, that is, in Ni-rich samples, leads to a corresponding increase in $\left(\theta_{D}\right)$. The observed increase in Debye temperature $\left(\theta_{D}\right)$ with nickel concentration $(x)$ in the range of $0.3 \leq x \leq 1.0$ suggested that lattice vibrations are hindered due to Ni-substitution. This may be due to the fact that strength of interatomic bonding increases with concentration $(x)$ as supported by our results on the variation of elastic moduli.

\section{Conclusion}

The single-phase cubic spinel formation of the compositions of the ferrite system, $\mathrm{Li}_{0.5-0.5 x} \mathrm{Ni}_{x} \mathrm{Fe}_{2.5-0.5 x} \mathrm{O}_{4}$ (where, $x=0$, $0.1,0.3,0.5,0.7,0.9$, and 1.0 ), has been confirmed from X-ray diffraction patterns. No impurity phases have been detected from X-ray charts. The lattice constant is constant over the whole range of Ni-substitution $(x)$. The experimental and theoretical lattice constants are in good agreement with each other confirming that the suggesting cation distribution is acceptable. X-ray density increases with Ni-substitution. The calculated values of particle size lie in the range 40 $59 \mathrm{~nm}$. The main absorption bands of spinel ferrite have appeared through IR absorption spectra recorded in the range of $1000-200 \mathrm{~cm}^{-1}$. The analysis of IR spectra indicates the presence of splitting in the absorption band due to the presence of small amounts of $\mathrm{Fe}^{2+}$ ions in ferrite. The force constants for tetrahedral and octahedral, elastic moduli, Debye temperature $\left(\theta_{D}\right)$, and transverse $\left(V_{t}\right)$ and longitudinal $\left(V_{l}\right)$ wave velocity have been determined. The variation of elastic moduli with composition has been interpreted in terms of binding forces between the atoms of spinal lattice.

\section{References}

[1] P. D. Baba, G. M. Argentina, W. E. Courtney, G. F. Dionne, and D. H. Temme, "Fabrication and properties of microwave lithium ferrites," IEEE Transactions on Magnetics, vol. MAG8, no. 1, pp. 83-94, 1972.

[2] Z. Yue, J. Zhou, X. Wang, Z. Gui, and L. Li, "Preparation and magnetic properties of titanium-substituted LiZn ferrites via a sol-gel auto-combustion process," Journal of the European Ceramic Society, vol. 23, no. 1, pp. 189-193, 2003.

[3] J. S. Baijal, S. Phanjoubam, D. Kothari, C. Prakash, and P. Kishan, "Hyperfine interactions and magnetic studies of Li-Mg ferrites," Solid State Communications, vol. 83, no. 9, pp. 679682, 1992.

[4] S. S. Bellad and R. B. Panja, "Structural and magnetic properties of some mixed Li-Cd ferrites," Materials Chemistry \& Physics, vol. 52, no. 2, pp. 166-169, 1998.

[5] R. S. Patil, S. V. Kakatkar, S. A. Patil, A. M. Sankpal, and S. R. Sawant, "X-ray and bulk magnetic studies on $\mathrm{Li}_{0.5} \mathrm{Zn}_{x} \mathrm{Ti}_{x} \mathrm{Fe}_{2.5-2 x} \mathrm{O}_{4}$, Materials Chemistry \& Physics, vol. 28, no. 4, pp. 355-365, 1991.

[6] Y. Purushottam and P. Krshan, "Electrical conductivity and thermopower studies of titanium-substituted lithium-magnesium ferrites," Materials Letters, vol. 17, p. 341, 1993.

[7] S. A. Mazen and H. A. Dawoud, "Structure and magnetic properties of Li-Cu ferrite," Physica Status Solidi (a), vol. 172, no. 2, pp. 275-289, 1999.

[8] S. A. Mazen, S. F. Mansour, E. Dhahri, H. M. Zaki, and T. A. Elmosalami, "The infrared absorption and dielectric properties of Li-Ga ferrite," Journal of Alloys and Compounds, vol. 470, no. 1-2, pp. 294-300, 2009.

[9] U. N. Trivedi, K. H. Jani, K. B. Modi, and H. H. Joshi, "Study of cation distribution in lithium doped nickel ferrite," Journal of Materials Science Letters, vol. 19, no. 14, pp. 1271-1273, 2000.

[10] P. V. Reddy, T. S. Rao, and Y. V. Ramana, "Ferrimagnetic Volume Change in Lithium-Nickel Ferrites," Current Science, vol. 46, p. 742, 1977.

[11] P. V. Reddy and T. S. Rao, "X-ray studies on lithium-nickel and manganese-magnesium mixed ferrites," Journal of the LessCommon Metals, vol. 75, no. 2, pp. 255-260, 1980.

[12] P. V. Reddy and T. S. Rao, "Dielectric behaviour of mixed Li-Ni ferrites at low frequencies," Journal of the Less-Common Metals, vol. 86, pp. 255-261, 1982.

[13] S. L. Kakani and C. A. Hemrajani, Text Book of Solid State Physics, Sultan Chand \& Sons, New Delhi, India, 3rd edition, 1997.

[14] K. B. Modi, U. N. Trivedi, M. P. Pandya, S. S. Bhatu, M. C. Chhantbar, and H. H. Joshi, Microwaves and Optoelectronics, Anamaya Publishers, New Delhi, India, 2004.

[15] S. A. Mazen, M. H. Abdallah, R. I. Nakhla, H. M. Zaki, and F. Metawe, "X-ray analysis and IR absorption spectra of Li-Ge ferrite," Materials Chemistry \& Physics, vol. 34, no. 1, pp. 3540, 1993.

[16] S. M. Patange, S. E. Shirsath, B. G. Toksha, S. S. Jadhav, S. J. Shukla, and K. M. Jadhav, "Cation distribution by Rietveld, spectral and magnetic studies of chromium-substituted nickel ferrites," Applied Physics A, vol. 95, no. 2, pp. 429-434, 2009. 
[17] B. D. Culity, Elements of X-Ray Diffraction, Addison-Wesely, 1959.

[18] M. M. Haque, M. Huq, and M. A. Hakim, "Densification, magnetic and dielectric behaviour of $\mathrm{Cu}$-substituted $\mathrm{Mg}-\mathrm{Zn}$ ferrites," Materials Chemistry \& Physics, vol. 112, no. 2, pp. 580-586, 2008.

[19] S. C. Watawe, B. D. Sarwade, S. S. Bellad, B. D. Sutar, and B. K. Chaugule, "Microstructure and magnetic properties of LiCo ferrites," Materials Chemistry \& Physics, vol. 65, no. 2, pp. 173-177, 2000.

[20] A. Dhahri, J. Dhahri, S. Zemni, M. Oumezzine, M. Said, and H. Vincent, "Synthesis, structural, magnetic and electrical properties of $\mathrm{La}_{1-x} \mathrm{Cd} d_{x} \mathrm{MnO}_{3}$ manganites $(0.1 \leq x \leq 0.5)$," Journal of Alloys and Compounds, vol. 450, no. 1-2, pp. 12-17, 2008.

[21] D. Ravinder, "Far-infrared spectral studies of mixed lithiumzinc ferrites," Materials Letters, vol. 40, no. 5, pp. 205-208, 1999.

[22] S. A. Mazen, "Tetravalent ions substitution in Cu-ferrite: structure formation and electrical properties," Materials Chemistry \& Physics, vol. 62, no. 2, pp. 131-138, 2000.

[23] P. Priyadharsini, A. Pradeep, P. S. Rao, and G. Chandrasekaran, "Structural, spectroscopic and magnetic study of nanocrystalline Ni-Zn ferrites," Materials Chemistry \& Physics, vol. 116, no. 1, pp. 207-213, 2009.

[24] S. C. Watawe, B. D. Sutar, B. D. Sarwade, and B. K. Chougule, "Infrared studies of some mixed Li-Co ferrites," International Journal of Inorganic Materials, vol. 3, no. 7, pp. 819-823, 2001.

[25] V.A. Potakova, N.D. Zverv, and V.P. Romanov, "On the cation distribution in $\mathrm{Ni}_{1-x-y} \mathrm{Fe} \mathrm{Zn}_{y} \mathrm{FeO}_{4}$ spinel ferrites," Physica Status Solidi (a), vol. 12, p. 623, 1972.

[26] P. Tarte, "Infra-red spectrum and tetrahedral coordination of lithium in the spinel $\mathrm{LiCrGeO}_{4}$, " Acta Crystallographica, vol. 16, p. 228, 1963.

[27] R. D. Waldron, "Infrared spectra of ferrites" Physical Review, vol. 99, no. 6, pp. 1727-1735, 1955.

[28] D. Ravinder and T. A. Manga, "Elastic behaviour of Ni-Cd ferrites," Materials Letters, vol. 41, no. 5, pp. 254-260, 1999.

[29] K. B. Modi, "Elastic moduli determination through IR spectroscopy for zinc substituted copper ferri chromates," Journal of Materials Science, vol. 39, no. 8, pp. 2887-2890, 2004.

[30] K. B. Modi, P. U. Sharma, M. C. Chhantbar, and H. H. Joshi, "Elastic constants determination for $\mathrm{Fe}^{3+}$ substituted YIG through infra-red spectroscopy and heterogeneous metal mixture rule," Journal of Materials Science, vol. 40, no. 5, p. 1247, 2005.

[31] B. Raj, V. Rajendram, and P. Palanichamy, Science and Technology of Ultrasonics, Narosa Publishing House, New Delhi, India, 2004.

[32] W. A. Wooster, "Physical properties and atomic arrangements in crystals," Reports on Progress in Physics, vol. 16, no. 1, pp. 62-82, 1953.

[33] K. B. Modi, M. K. Rangolia, M. C. Chhantbar, and H. H. Joshi, "Study of infrared spectroscopy and elastic properties of fine and coarse grained nickel-cadmium ferrites," Journal of Materials Science, vol. 41, no. 22, pp. 7308-7318, 2006. 

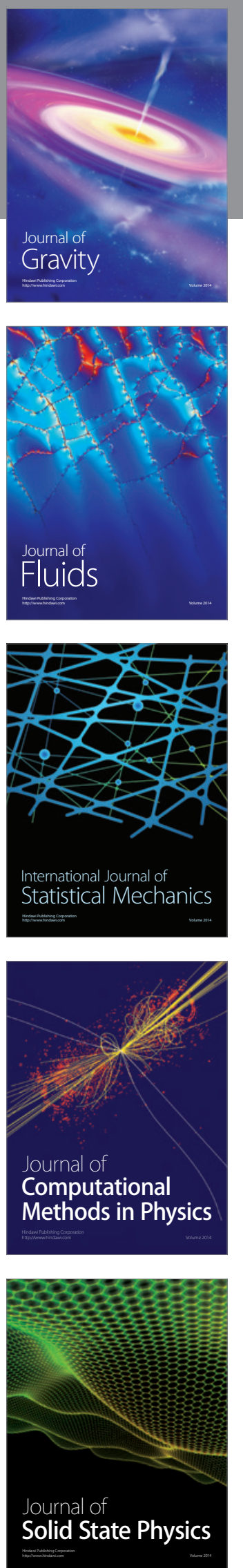
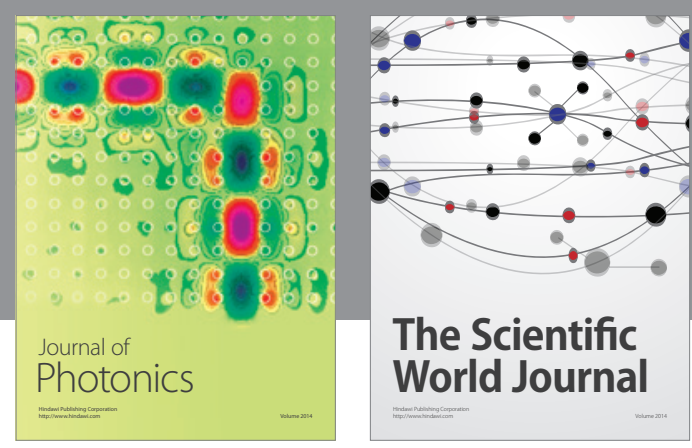

The Scientific World Journal

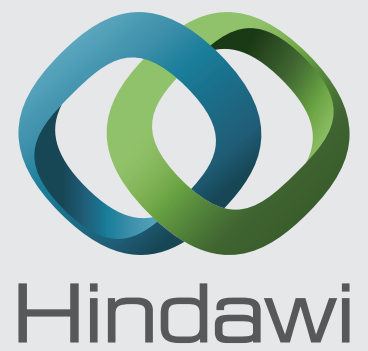

Submit your manuscripts at http://www.hindawi.com
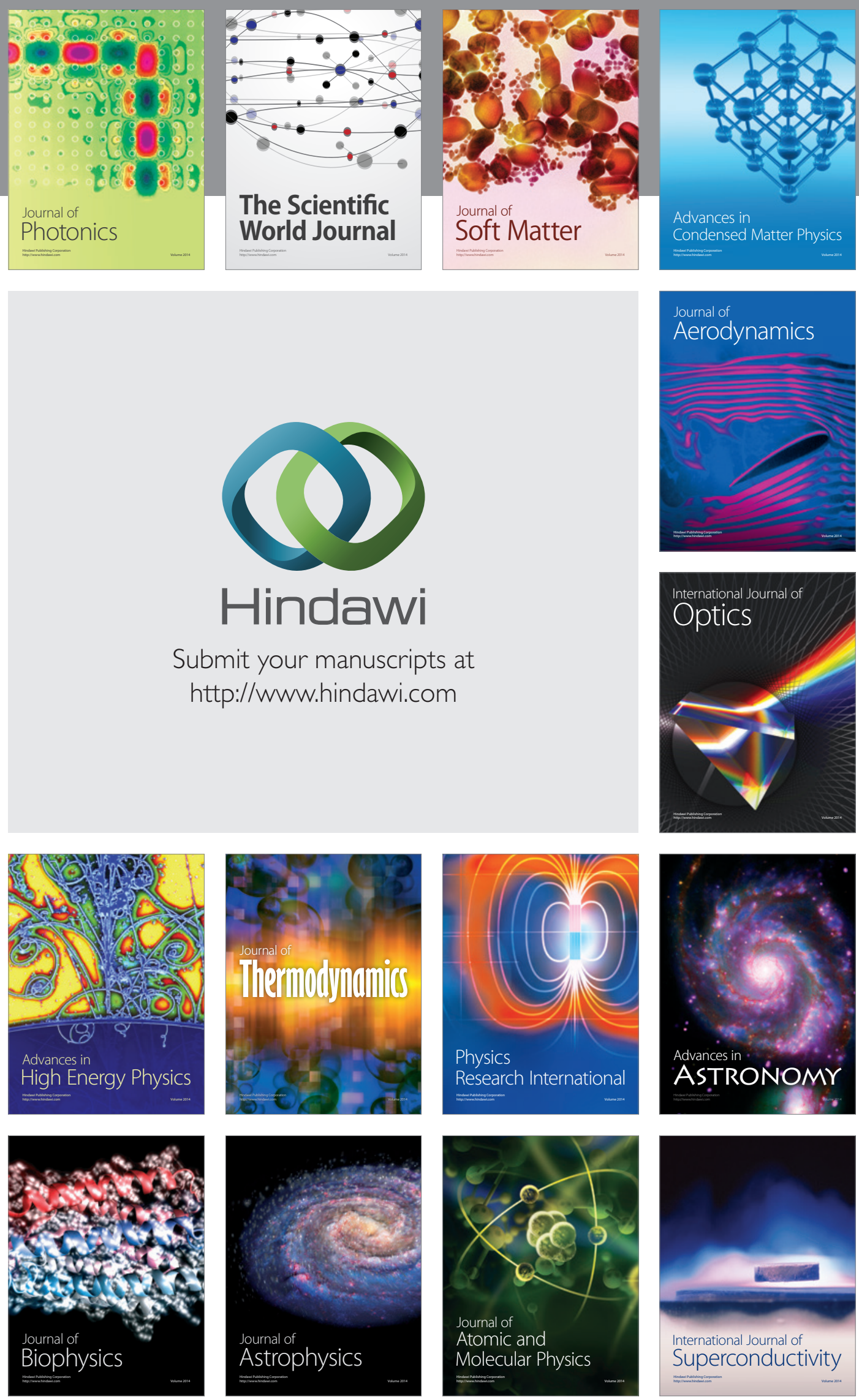
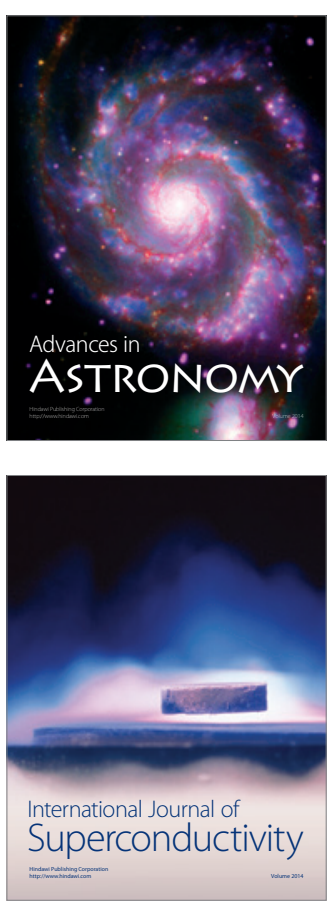